\title{
Origin of the SuperDARN broad Doppler spectra: simultaneous observation with Oersted satellite magnetometer
}

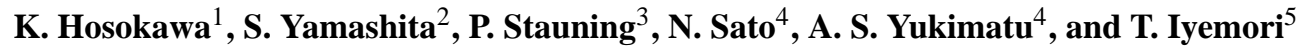 \\ ${ }^{1}$ Department Information and Communication Engineering, The University of Electro-Communications, Tokyo, Japan \\ ${ }^{2}$ Department of Geophysics, Graduate School of Science, Kyoto University, Kyoto, Japan \\ ${ }^{3}$ Danish Meteorological Institute, Copenhagen, Denmark \\ ${ }^{4}$ National Institute of Polar Research, Tokyo, Japan \\ ${ }^{5}$ Data Analysis Center for Geomagnetism and Space Magnetism, Graduate School of Science, Kyoto University, Kyoto, Japan
}

Received: 18 October 2002 - Revised: 28 May 2003 - Accepted: 2 June 2003 - Published: 1 January 2004

\begin{abstract}
We perform a case study of a favorable conjunction of an overpass of the Oersted satellite with the field-ofview of the SuperDARN Syowa East radar during an interval of the southward IMF $B_{z}$. At the time, the radar observed an L-shell aligned boundary in the spectral width around the dayside ionosphere. Simultaneously, high-frequency (0.2$5 \mathrm{~Hz}$ ) magnetic field fluctuations were observed by the Oersted satellite's high-time resolution magnetometer. These magnetic field fluctuations are considered to be Alfvén waves possibly associated with the particle which precipitates into the dayside high-latitude ionosphere when magnetic reconnection occurs. It has been theoretically predicted that the time-varying electric field is the dominant physical process to expand the broad HF radar Doppler spectra. Our observation clearly demonstrates that the boundary between narrow and broad spectral widths is corresponding well to the boundary in the level of the fluctuations, which supports the previous theoretical prediction. A close relationship between electric and magnetic field fluctuations and particle precipitations during southward IMF conditions has been confirmed by many authors. The present observation allows us to suggest that the boundary between narrow and broad Doppler spectral widths observed in the dayside ionosphere is connected with the signature of the open/closed field line boundary, such as the cusp particle precipitations via electric and magnetic field fluctuations for the case of the negative IMF $B_{z}$ conditions.
\end{abstract}

Key words. Ionosphere (ionosphere-magnetosphere interactions; plasma convection). Magnetospheric physics (magnetopause, cusp, and boundary layers)

\section{Introduction}

The HF coherent scatter radars of the Super Dual Auroral Radar Network (SuperDARN, Greenwald et al., 1995) often

Correspondence to: $\mathrm{K}$. Hosokawa

(hosokawa@ice.uec.ac.jp) observe broad, complex Doppler spectra within the dayside and nightside high-latitude ionosphere. Baker et al. (1995) pointed out that the dayside polar cusp, as defined by lowaltitude satellite particle precipitation data (e.g. Newell and Meng, 1991), is characterized by these broad and complex Doppler spectra in the coherent HF radar observations. They also showed that regions equatorward of the cusp are usually found to have narrow Doppler spectra dominated by a single component. The equatorward edge of these HF radar backscatters with broad spectra appears to correspond closely to the equatorward edge of the red line $(630 \mathrm{~nm})$ aurora during the period of negative IMF $B_{z}$ (Rodger et al., 1995; Milan et al., 1999; Moen et al., 2001). These observational facts enable recent studies to use the boundary between narrow and broad Doppler spectral widths (hereinafter referred to as spectral width boundary: SWB) as a proxy for the open/closed field line boundary within the dayside ionosphere. This relationship has been widely employed to estimate several geophysical parameters, such as (1) reconnection electric field (Baker et al., 1997; Pinnock et al., 1999); (2) the form and size of the polar cap (Chisham et al., 2001; Milan et al., 2003); (3) the creation and destruction rate of open magnetic flux associated with the dayside and nightside reconnection (Hosokawa et al., 2003). However, our knowledge about the origin of the HF radar broad Doppler spectra is still not sufficient.

In general, these broad spectra could be related to both temporal variability of the convection electric field and spatial variation of the plasma convection within a single radar range cell. André et al. (1999, 2000a, 2000b) theoretically modeled the impact of various kinds of physical processes on the width of the HF radar Doppler spectra. They concluded that the broad spectral widths observed in the dayside highlatitude ionosphere result predominantly from a time-varying electric field in the Pc1-2 frequency range, whereas the other factors, such as the velocity shears within the radar cells and microscale turbulence, also make additional contributions. The fluctuating electric field employed in their modeling and the accompanying magnetic field fluctuations are continu- 
ously observed in the vast area of the dayside high-latitude region by low-altitude (e.g. Maynard et al., 1982; Maynard, 1985; Maynard et al., 1991; Erlandson and Anderson, 1996) and polar-orbiting (e.g. Matsuoka et al., 1991; 1993) satellites. However, a one-to-one relationship between the HF radar broad spectral width and the electric and magnetic field fluctuations has not been confirmed by substantial observations. In this study, we have investigated high-resolution magnetic field observations from the Oersted satellite, in conjunction with the broad spectral width as observed by the SuperDARN Syowa East radar in Antarctica. Consequently, we have found a very close relationship between the broad spectral width and the magnetic field fluctuations within the dayside ionosphere during an interval of negative IMF $B_{z}$.

\section{Instrumentation}

This paper presents a single event of the SWB observation from the SENSU (Syowa-East radar of Syowa-South \& East HF Radars of NIPR for SuperDARN) Syowa East radar in Antarctica $\left(69.01^{\circ} \mathrm{S} ; 39.61^{\circ} \mathrm{E}\right)$. The radar is part of the $\mathrm{Su}-$ perDARN, which covers a vast portion of the northern and southern auroral zones and polar cap. On the day presented in this paper (22 January 2000), the radar was operating in a normal scan mode. In the current version of this scan mode the radars carry out azimuthal sweeps through discrete beam pointing directions that are numbered $0-15$, with a step in azimuth of approximately $3.33^{\circ}$. It takes approximately $7 \mathrm{~s}$ to integrate backscatter returns in one direction and about $2 \mathrm{~min}$ are needed to do a scan of all directions. In SENSU radars, 70 range gates are sampled for each beam with a pulse length of $300 \mu \mathrm{s}$, which is equivalent to a gate length of $45 \mathrm{~km}$, and a lag to the first gate of $1200 \mu \mathrm{s}(180 \mathrm{~km})$. In this configuration the maximum range of the radars is approximately $3550 \mathrm{~km}$. Hence, the radar field-of-view in each scan contains 1120 cells (70 ranges $\times 16$ beams). A seven pulse scheme is transmitted and an analysis of the autocorrelation function (ACF) of the returned signals (FITACF; see Baker et al., 1988 and Villain et al.,1987) yields backscatter power, Doppler velocity and spectral width.

The Oersted satellite was launched on 23 February 1999 into a polar orbit whose inclination is $96.5^{\circ}$. The ascending node was initially located at 14:11 LT. The orbital plane drifts at a rate of $-0.88 \mathrm{~min}$ per day. The initial perigee and apogee were $638 \mathrm{~km}$ and $849 \mathrm{~km}$, respectively. The orbital period is about $100 \mathrm{~min}$. The magnetometer data used in this analysis are the radial $(r)$, southward $(\theta)$, and eastward $(\phi)$ components sampled at every $39.25 \mathrm{~ms}$ (approximately $25 \mathrm{~Hz}$ ). The original data are described in the geographic coordinates and the data used in this analysis are transformed into the geomagnetic dipole coordinates. The residuals $\left(\Delta B_{r}, \Delta B_{\theta}\right.$ and $\Delta B_{\phi}$ ) from the geomagnetic main field were calculated by using the Oersted (10c/99) model. The Oersted (10c/99) model is a geomagnetic main field model which consists of the OIFM (the Oersted initial field model, Olsen et al., 2000) and secular variation.

\section{Observations}

The top four panels of Fig. 1 show the variation in the IMF $B_{x}, B_{y}, B_{z}$ and solar wind dynamic pressure monitored by ACE spacecraft located upstream of the Earth's magnetosphere $\left(\mathrm{X}_{\mathrm{GSM}}=239.79, \mathrm{Y}_{\mathrm{GSM}}=14.70, \mathrm{Z}_{\mathrm{GSM}}=18.98\right)$. An approximate solar wind velocity of $380 \mathrm{~km} \mathrm{~s}^{-1}$, measured by the spacecraft, gives a delay of 74 minutes between the observation of IMF features and their incidence on the Earth's magnetopause (calculation is based on the method outlined by Khan and Cowley, 1999). The IMF $B_{z}$ component was predominantly negative for the entire interval, except for a brief positive excursion at 06:32 and 06:50 UT.

The bottom two panels present the spectral width and line-of-sight Doppler velocity observed along beam 5 of the SENSU Syowa East radar from 05:30 to 07:30 UT on 22 January 2000, where only backscatters from the ionospheric irregularities are shown (i.e. echoes regarded as ground scatter have been eliminated). The spectral width is colour coded with blue representing the narrowest spectral widths and red indicating the widest. The line-of-sight velocity is also colour coded with green/blue indicating the velocity toward the radar, and yellow/red indicating the velocity away from the radar. A vertical dashed line indicates the time when the Oersted satellite traversed the radar field-of-view at 06:22 UT. During the interval of the Oersted overpass, the broad spectral width region at higher latitude (characterized by a mixture of the colours such as yellow and red) is clearly distinct from the narrow spectral width region at lower latitude (characterized by an almost uniform blue appearance), and a well-defined SWB can be identified.

Figure 2 displays a map of the spectral width (top) and line-of-sight Doppler velocity (bottom) at 06:22 UT in a magnetic latitude and local time coordinate system (AACGM geomagnetic coordinate system based on Baker and Wing, 1989), as observed by all of the beams of the SENSU Syowa East radar. Overlaid are the footprints of the Oersted spacecraft mapped down to the altitude of the SuperDARN observations (assumed to be $400 \mathrm{~km}$ in this case) using the Tsyganenko 96 model (Tsyganenko, 1995). SWB is observed in the dawn meridian between 06:20 and 08:20 MLT, and it clearly exhibits an L-shell aligned structure. A dashed line traces the approximate position of the SWB, with the magnetic latitude being approximately $71.5^{\circ}$. The line-ofsight velocity also changed drastically across the SWB. On the poleward side of the SWB, velocity is $500-750 \mathrm{~m} \mathrm{~s}^{-1}$ away from the radar. On the other side of the SWB (equatorward side), the velocity is very small $\left(\approx 100 \mathrm{~m} \mathrm{~s}^{-1}\right)$, suggesting that the convective flow is directed mostly zonal. The spacecraft is flying from a high-latitude region to the lowlatitude and crosses the SWB at 06:22 UT (magnetic local time $\approx 07: 45 \mathrm{MLT}$ ). In the next part of this section, we compare the magnetic field data obtained from Oersted and structure of the SWB for the interval of the approach of the satellite to the SWB.

The top three panels of Fig. 3 show three components of high-time resolution magnetic field observations from the 


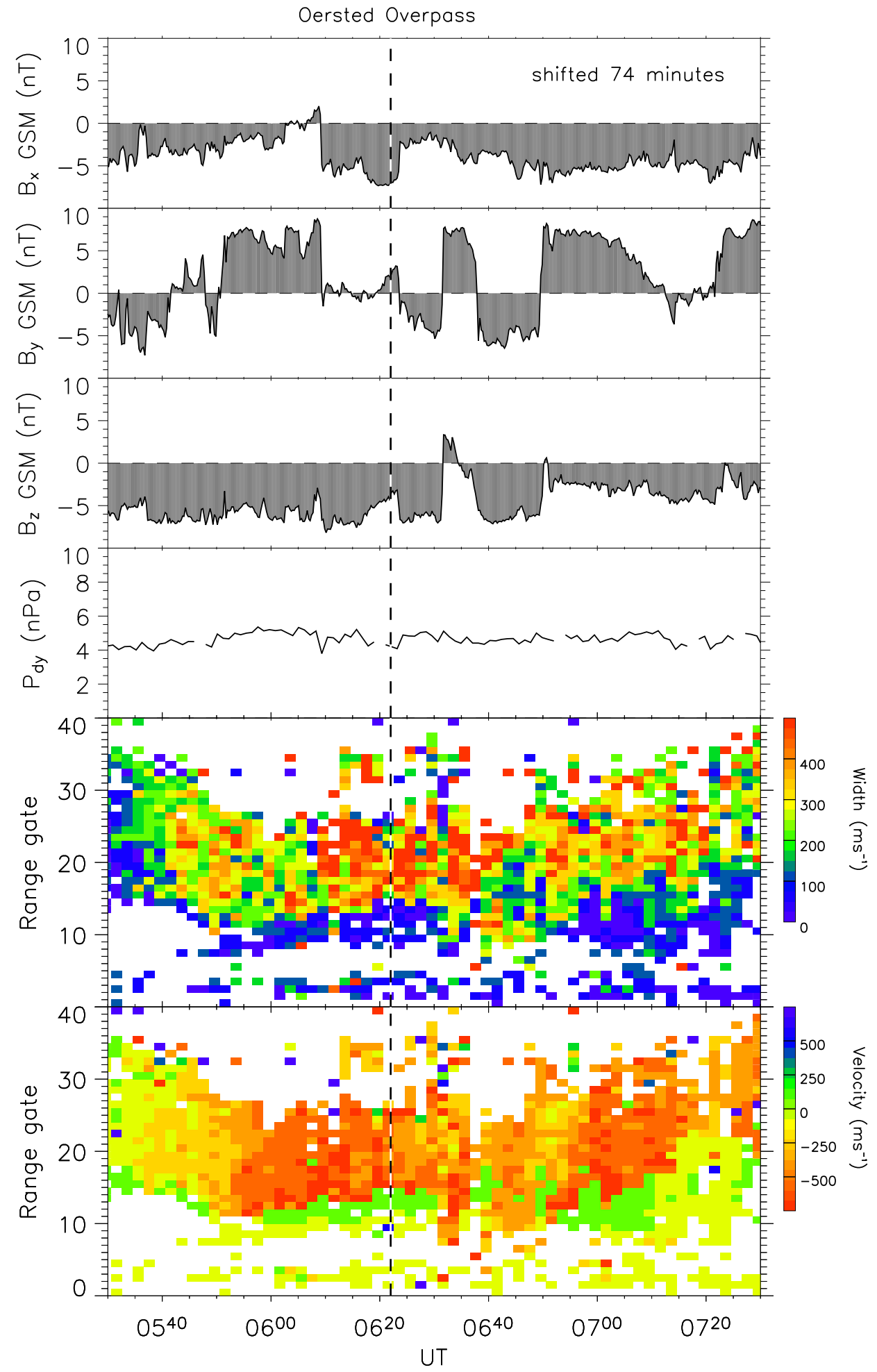

Fig. 1. (Top four panels): The $B_{x}, B_{y}$, and $B_{z}$ components of the IMF and solar wind dynamic pressure as measured by the ACE spacecraft lagged to the magnetopause. (Bottom two panels): The spectral width and line-of-sight Doppler velocity observed along beam 5 of the SENSU Syowa East radar during the interval of the present study, 05:30 to 07:30 UT, 22 January 2000. Vertical dashed line indicates the time of the Oersted crossing of the spectral width boundary at 06:22 UT. 

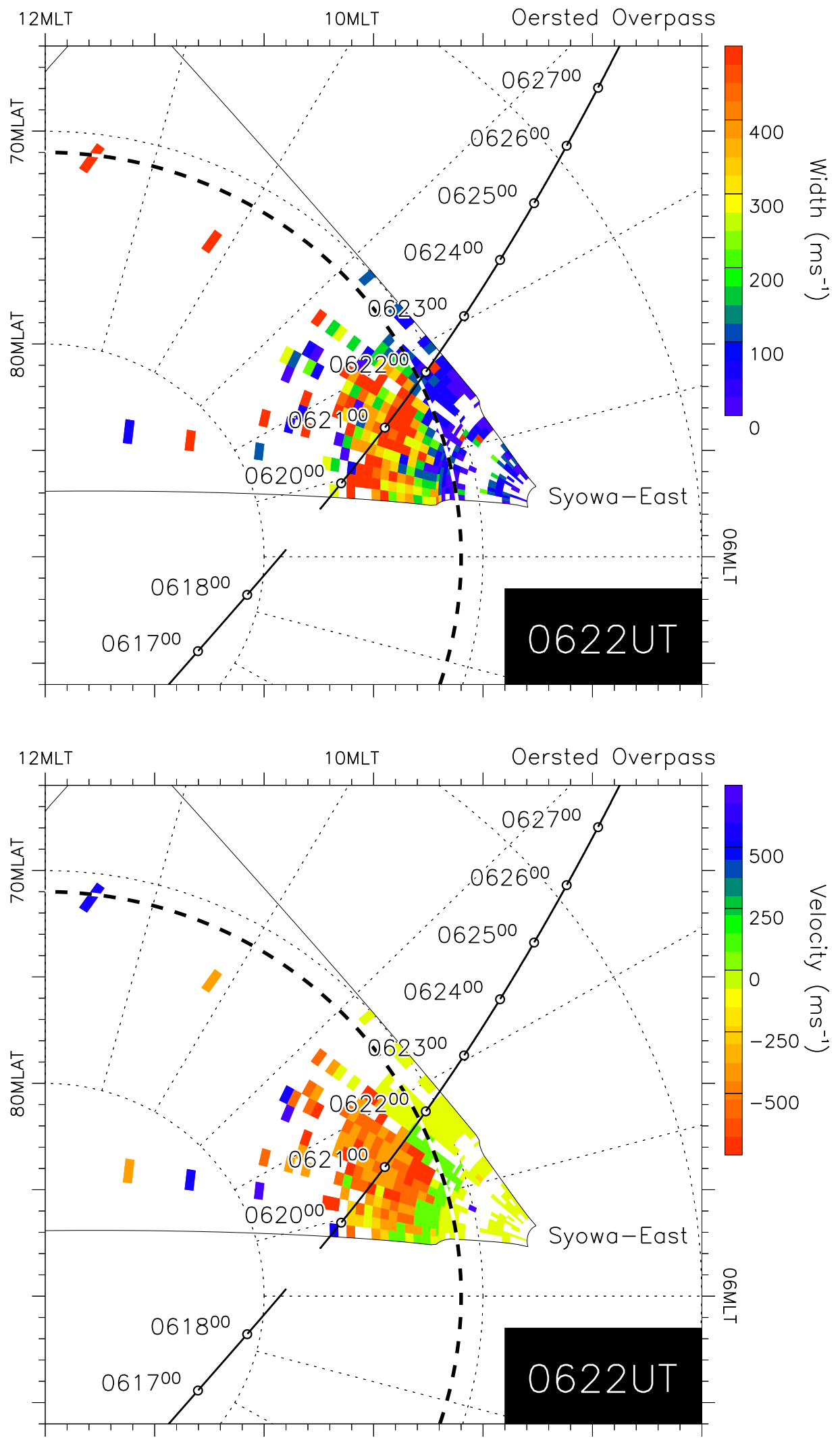

Fig. 2. Maps of spectral width (top) and line-of-sight Doppler velocity (bottom) as observed by all of the beams of the SENSU Syowa East radar at 06:22 UT in a magnetic latitude and magnetic local time coordinate system. Overlaid black line represents the footprints of the Oersted spacecraft mapped down to the altitude of the SuperDARN observations using the Tsyganenko 96 model. Dotted circle traces an approximate location of the spectral width boundary. 
Oersted spacecraft around the crossing of the SWB (from 06:17 to 06:26 UT). Grey-shaded bars at the bottom of each panel display the standard deviation of the variation calculated for every 2 seconds in duration (i.e. 50 samples). The vertical dashed line indicates the time when Oersted crosses the SWB. It is found that the fluctuating magnetic field is observed before the crossing of the SWB. These fluctuations suddenly cease just after the SWB crossing. This sudden change is most clearly seen in the variation of the standard deviation. Fluctuations are observed in all components, however, they are more prominent in $\theta$ (north-south) and $\phi$ (eastwest) components rather than that in the $r$ (radial) component. The other item worth noting is that the level of fluctuations are also low in the highest latitude part of the Oersted track. Since there exists a data gap from 06:18:50 UT to 06:19:32 UT, we cannot exactly determine when the fluctuation started to be observed. However, large amplitude fluctuating magnetic fields are not seen in the magnetic latitude above $80^{\circ}$. This characteristics is consistent with the past observations of the fluctuating electric field (e.g. Maynard et al., 1991; Matsuoka et al., 1993).

Another point is that the magnetic field fluctuations and large-scale field-aligned current structure seem to have a relationship. A large, positive variation is identified in the east-west component around the SWB, which suggests that a large-scale field-aligned current pair exists near the boundary of the fluctuation and spectral width. The changes in $\Delta B_{\theta}$ are small compared with those in $\Delta B_{\phi}$, indicating that the current sheet is nearly parallel to the L-shell. The bottom panel of Fig. 3 displays a time series of field-aligned current (FAC) density calculated from the transverse magnetic field disturbance for every 5 seconds. On the poleward side of the SWB, the direction of the FAC is mostly downward. In contrast, upward FAC dominates the region equatorward of the SWB. This set of downward and upward FACs is consistent with the cusp FAC system established during negative IMF $B_{z}$ and positive IMF $B_{y}$ conditions (e.g. Trondsen et al., 1999). Magnetic latitude of the boundary between the two FAC current sheets is almost equal to that of the SWB, suggesting that the SWB is related to the open/closed field line boundary (Lyatsky et al., 1974; Trondsen et al., 1999). The magnitude of the FAC density is up to $5 \times 10^{-6} \mathrm{~A} \mathrm{~m}^{-2}$.

In order to clarify the dominant frequency band of the fluctuations seen in the Oersted observation, dynamic spectra of the $\Delta B_{\theta}$ component in the frequency range between $0.2 \mathrm{~Hz}$ and $5 \mathrm{~Hz}$ are displayed in the bottom panel of Fig. 4, where the Fourier transform interval is 10.08 seconds (corresponding to 256 samples). An expanded plot of the $\Delta B_{\theta}$ component around the SWB (1-minute interval from 06:21:30 to 06:22:30 UT) is also presented in the top panel of Fig. 4 for comparison. Vertical dashed line in each panel gives the time when the satellite traverses the SWB. It is again clearly found in the top panel that the fluctuation suddenly terminates when the satellite crosses the SWB. The equatorward boundary of the fluctuation is considerably sharp, which is consistent with the previous observations (e.g. Maynard et al., 1991). Spectral characteristics of these fluctuations have no distinct fre- quency peak and tend to be broad-band, however, the contribution becomes smaller as the frequency increases. This feature is basically in good agreement with the previous studies of the fluctuating electric field within the cusp (e.g. Maynard et al., 1985).

\section{Discussion}

Intense electric and magnetic field fluctuations in the Pc1 frequency range have been observed over the dayside cusp by low-altitude, polar-orbiting satellites (Sugiura et al., 1982; Maynard et al., 1982; Maynard, 1985; Maynard et al., 1991; Matsuoka et al., 1991; Ishii et al., 1992; Matsuoka et al., 1993; Erlandson and Anderson, 1996). These previous observations indicate that the orthogonal components of the magnetic and electric field perturbations are highly correlated. The present observation demonstrated that a highly fluctuating magnetic field is observed in the vicinity of the broad spectral width region. In paricular, the equatorward boundary of the fluctuation is closely corresponding to the SWB in the radar observations, suggesting that the HF radar broad spectral width is associated with the same kind of fluctuations in the electric field. However, a theoretical explanation for the relationship between fluctuations in the electric and magnetic fields must be needed because no substantial electric field observation was available during the interval of this study. In general, electromagnetic waves whose wave vector $\boldsymbol{k}$ is parallel to the electric field do not have an oscillating component in the magnetic field (electrostatic waves). On the other hand, the electric field component does not vanish, even if the wave vector $\boldsymbol{k}$ is parallel to the magnetic field. This is due to the fact that the magnetic field can be generated from two sources, i.e. electric current and time-varying electric field. Hence, waves that have an oscillating component only in the magnetic field one cannot exist in the terrestrial plasma medium, which indicates that time-varying electric field must exist in the region of the magnetic field fluctuation and the broad spectral width during the present interval.

The other important issue to be discussed is that the level of magnetic field fluctuation is also low in the magnetic latitudes above $80^{\circ}$. Hosokawa et al. (2002) carried out a statistical analysis of the HF radar spectral width and reported that the spectral width is small above $80^{\circ}$ magnetic latitude. McWilliams et al. (2001a) investigated poleward moving pulsed ionospheric flows (PIFs) in the HF radar data and pointed out that the spectral widths are relatively high at the equatorward edge of the PIFs, but decrease with increasing latitude. Milan et al. (2002) analyzed HF radar polar patches and clearly showed that the spectral width within the patch becomes considerably narrow as it moves poleward. The nature of the fluctuating magnetic field observed in the present study is in good agreement with the low spectral widths at the highest part of the HF radar observation commonly identified in the previous studies.

Origin of these fluctuating fields is still under considerable debate. Three models for the generation of these fluctu- 


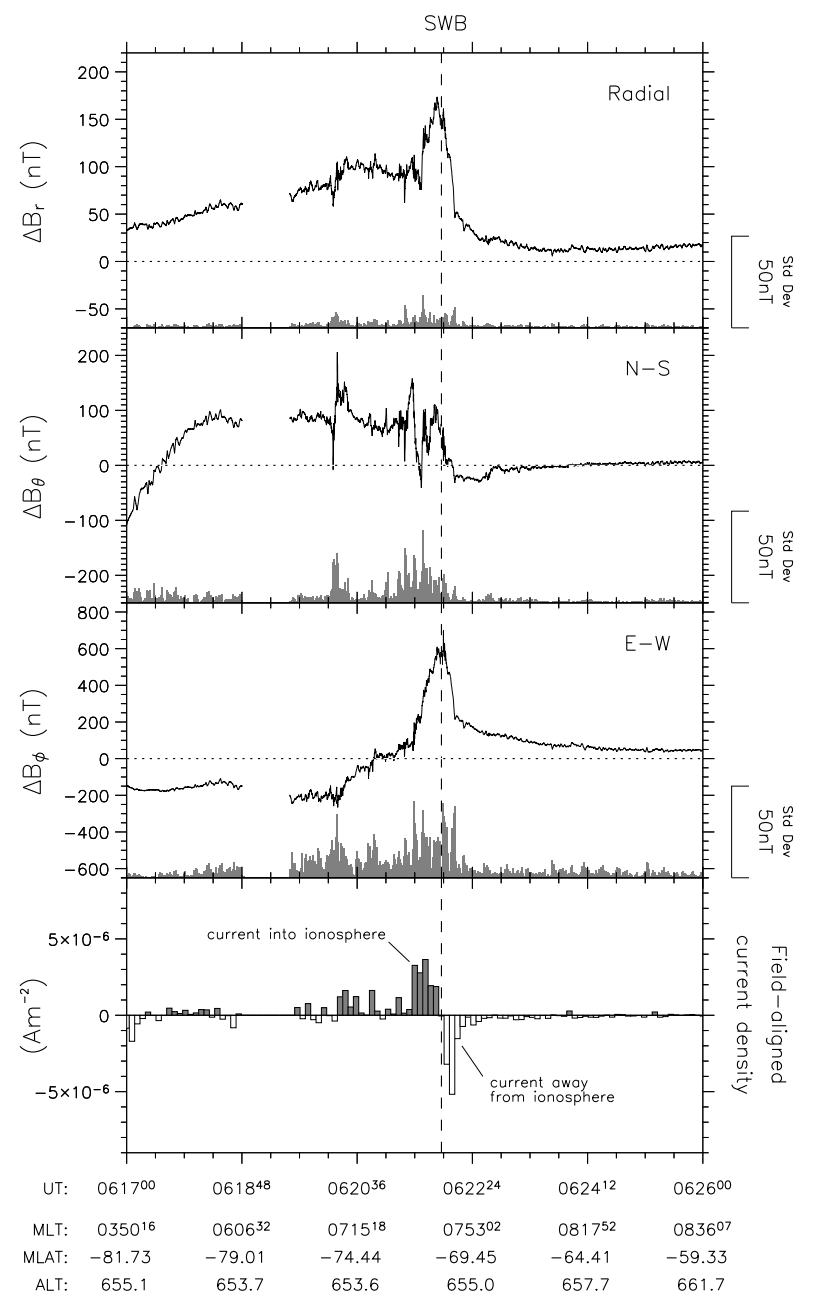

Fig. 3. (Top three panels): Three components of high-time resolution magnetic field observations from the Oersted satellite around the crossing of the spectral width boundary, from 06:17 to 06:26 UT. Grey-shaded bars at the bottom of each panel display the standard deviation of the variation calculated for every 2 seconds in duration (i.e. 50 samples). The vertical dashed line indicates the time when the Oersted crosses the spectral width boundary. (Bottom panel): Time-series of field-aligned current (FAC) density calculated from the transverse magnetic field variations for every 5 seconds.

ations have been put forward. At first, we consider the possibility that FAC itself produces the magnetic field fluctuations via high-frequency electrostatic instability in the topside ionosphere. Pilipenko et al. (1999) reported that densities of FAC $\approx 10^{-5}-10^{-6} \mathrm{~A} \mathrm{~m}^{-2}$ are sufficient for the excitation of Bunemann, ion-acoustic, or ion cyclotron instabilities. If we follow the theoretical estimation by Pilipenko et al. (1999), maximum FAC density shown in the bottom panel of Fig. 3 is large enough to produce the magnetic field fluctuations. However, there is not always a one-to-one clear correlation between FAC magnitude and the level of the fluctuations throughout the interval. In addition, magnetic field fluctuations are actually observed when the FAC density does not exceed the threshold for the instabilities $\left(10^{-6} \mathrm{~A} \mathrm{~m}^{-2}\right)$. Therefore, this process is not a primary generation mechanism of the fluctuations during the present interval, although a fraction of the fluctuations could be due to the coupling with large-scale FAC.
The second model assumes that the fluctuations are observed due to the orbital motion of the satellite through smallscale quasi-static field-aligned current structures embedded in the large-scale field-aligned current (Smiddy et al., 1980; Sugiura et al., 1982; Ishii et al., 1992). This is a space and time ambiguity in the satellite observation, not an actual wave in the ionosphere. As for the frequency range of $0.6 \mathrm{~Hz}$ (one of the dominant frequency bands in Fig. 4), the spatial scale length of the fluctuations is approximately $11 \mathrm{~km}$. This length is well below the size of radar range cells $(\approx 45 \mathrm{~km})$. These small-scale FACs are capable of producing small-scale vortex structures in the convective flow pattern of the ionosphere plasma. Some previous studies of HF radar spectra have attributed double-peaked spectra to vortices less than the scale size of the radar range cells (Schiffler et al., 1997; Huber and Sofko, 2000). André et al. (2000a) pointed out that the vortices smaller than the size of the radar range cells could also produce broad and complex Doppler spectra. 


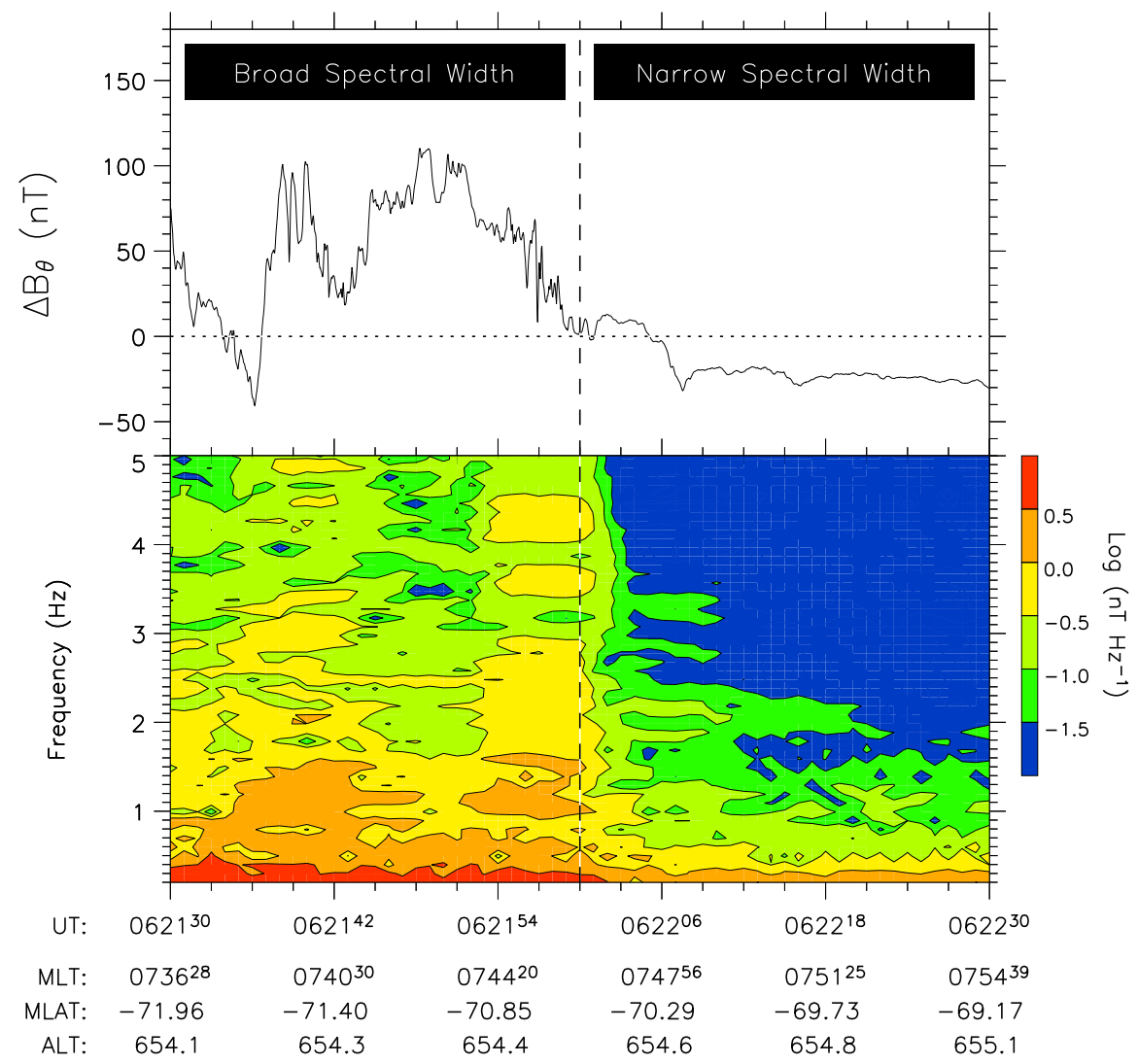

Fig. 4. (Top panel): An expanded plot of the $\Delta B_{\theta}$ component (1-min interval from 06:21:30 to 06:22:30 UT). (Bottom panel): Dynamic spectra of the $\Delta B_{\theta}$ component in the frequency range between 0.2 and $5 \mathrm{~Hz}$. The vertical dashed line indicates the time when Oersted crosses the spectral width boundary at 06:22 UT.

The third model suggests that disturbances in the distant magnetosphere are transmitted to the ionosphere as Alfvén waves (Lysak and Dum, 1983). Matsuoka et al. (1993) emphasized from the polar-orbiting satellite EXOS-D measurement that the electric to magnetic field ratios in the frequency range of $0.5-3 \mathrm{~Hz}$ agree well with the Alfvén velocity at the observation point. In general, it is difficult to distinguish between temporal and spatial variations in the satellite observation. However, Ishii et al. (1992) demonstrated that the Alfvén wave model is applicable to variations of scale lengths less than $4.0 \mathrm{~s}$, while the effect of the quasi-static model becomes increasingly dominant for a scale length greater than $8.0 \mathrm{~s}$. Hence, as for the dominant frequency range of the fluctuation as displayed in Fig. 4, the primary source of the fluctuation is considered to be the downward propagating Alfvén waves.

Next, we consider a relationship among various kinds of observations, such as the fluctuating electric and magnetic fields, precipitating ions and electrons, $630 \mathrm{~nm}$ cusp auroral luminosity, ionospheric convection, and HF radar broad spectral width. Maynard et al. (1982) have mentioned that the region of highly variable electric fields observed below the $900 \mathrm{~km}$ altitude on the dayside high-latitude region is associated with large fluxes of low energy electrons and field- aligned current structures. Matsuoka et al. (1993) have investigated the correlation between wave activities and the enhancement of the flux of precipitating ions and electrons simultaneously observed by the EXOS-D satellite. They reported that when the latitude of the cusp is low and the IMF is expected to be southward, the correlation coefficient is high, yet when the latitude of the cusp is high and the IMF is expected to be northward, then the correlation is poor. This fact suggests that the waves are observed in association with the injection of particles into the magnetosphere, when the IMF $B_{z}$ is negative and low-latitude reconnection occurs. On the other hand, previous studies have shown that the equatorward edge of the radar backscatter showing a broad Doppler spectral width is coincident with the equatorward edge of the cusp particle precipitation (Baker et al., 1995; Yeoman et al., 1997) and the $630 \mathrm{~nm}$ cusp auroral emissions (Rodger et al., 1995; Milan et al., 1999; Moen et al., 2001). However, Moen et al. (2001) pointed out from a comparison of dayside auroral activity and HF radar backscatter that this good relationship breaks down for northward IMF conditions.

Before discussing the relationship between the broad spectral width, magnetic field fluctuation, and other signatures of the cusp in detail, we must examine whether or not the region of the broad Doppler spectra actually belongs to the cusp (or 


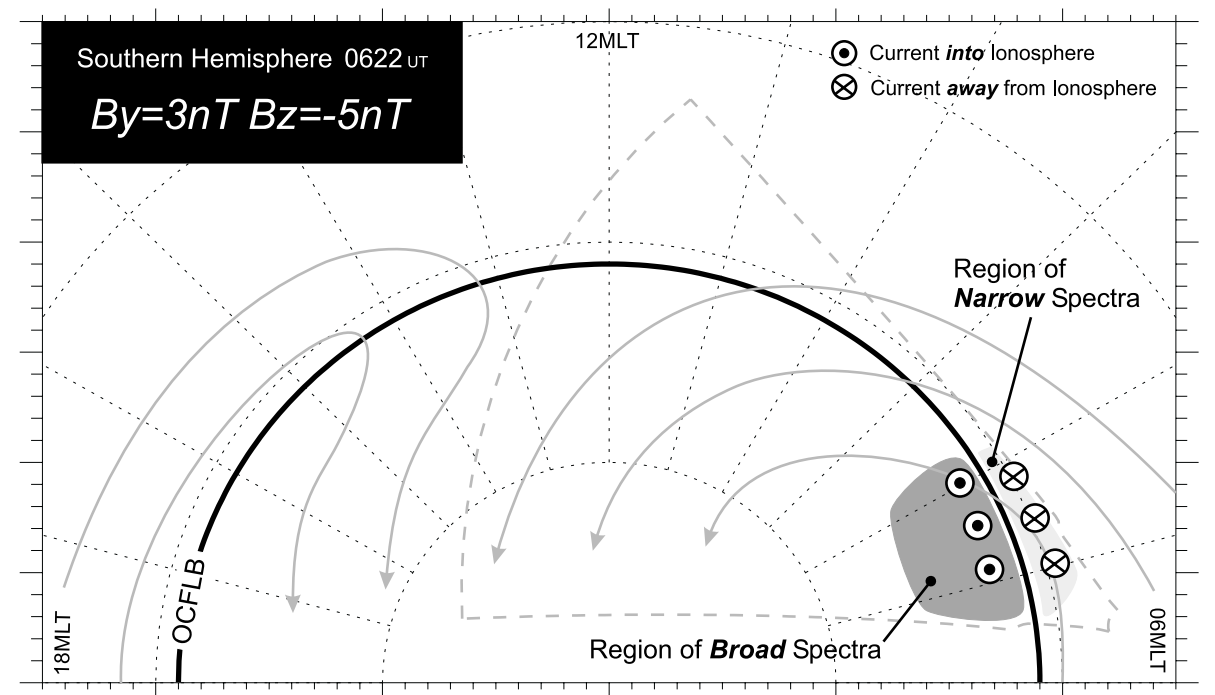

Fig. 5. Schematic illustration indicating how ionospheric convection, field-aligned current and spectral width boundary relate. Magnetic local noon is toward the top of the figure. Light grey curved arrows indicate the stream line of the ionospheric convection. Dotted fan-shaped region is the field-of-view of the SENSU Syowa East radar. Light grey shading indicates the region of narrow Doppler spectra and dark grey shading indicates the region of broad spectra.

footprint of the open-closed field line boundary: OCFLB). At first, we compare the latitude of the SWB with that of the OCFLB estimated from MHD simulation. At the time of the Oersted crossing, IMF $B_{z}$ is $\approx-5 \mathrm{nT}$ and solar wind dynamic pressure $\approx 5 \mathrm{nPa}$. If we refer to the MHD simulation by Palmroth et al. (2001), the magnetic latitude of the OCFLB is approximately $74^{\circ}$ at subsolar position. On the other hand, the probable latitude of the SWB was $72^{\circ}$ at the time of the Oersted crossing. There exists an offset between the modeling and the present observation of $2^{\circ}$. This could be because the observation had been done in the dawn side $(\approx 08$ MLT). In general, the equatorward edge of the polar cap (ideally this corresponds to the poleward edge of the auroral oval) is not a circle. Latitudes are slightly different against magnetic local time. If we consider the model of the auroral oval (e.g. Feldstein and Starkov, 1967), for example, the latitude of the poleward edge of the oval is found to be highest at magnetic local noon. The difference between local noon and dawn side ( 8 MLT) is approximately $2^{\circ}$ in magnetic latitude. This value is consistent with the offset between Palmroth's modeling and the current observation. Then, the position of the SWB is consistent with that of the OCFLB, on average.

Here, we discuss how the dayside convection pattern relates to the spectral width. At the time of the Oersted crossing of the SWB, IMF $B_{y}$ is directed positive $(\approx 3 \mathrm{nT})$. This implies that the convection cell is expanded in the dawn side. Then, plasma flow is directed mostly eastward in the cusp region, which is consistent with the observed line-of-sight velocity up to $750 \mathrm{~m} \mathrm{~s}^{-1}$ away from the radar. The relationship between the convective flow and the radar field-of-view is schematically illustrated in Fig. 5. In fact, the convection reversal boundary (or signature of the cusp) would be difficult to identify because of the expansion of the dawn side convection cell. As seen in the bottom panel of Fig. 2, however, the line-of-sight velocity changes drastically across the SWB, and the convection velocity poleward of the SWB is much larger than that equatorward of the boundary. This suggests that the region poleward of the SWB belongs to the regime of open field lines. McWilliams et al. (2001b) have shown that the duskward propagating reconnection site is observed irrespective of the sign of IMF $B_{y}$. They speculated that the reconnection site propagates azimuthally, both in the prenoon and postnoon sectors. In fact, Milan et al. (2003) have demonstrated that the poleward moving auroral form (ionospheric manifestation of the transient reconnection) can be observed on the dawn side $(\approx 7$ MLT) for negative IMF $B_{y}$ conditions. These previous observations imply that the reconnection occurs on a wide range of magnetic local times on the dayside. Hence, it is natural to consider that the SWB in the present observation is located at the footprint of the magnetopause reconnection $\mathrm{X}$-line.

The present observation demonstrated that the HF radar broad Doppler spectral width is closely connected to the time-varying magnetic field. Taking into account previous observations and the results of the present study, we can speculate that the HF radar broad Doppler spectra represents characteristics of cusp particle precipitations and corresponding $630 \mathrm{~nm}$ auroral emissions via reconnection-induced electric and magnetic field fluctuations for the case of the southward IMF conditions. To fully resolve this issue, more detailed analysis using data of the electric field, particle precipitation, aurora and HF radar spectral width is necessary. 


\section{Summary and conclusion}

Doppler spectral width observed by the SuperDARN radars and magnetic field fluctuations observed by the Oersted satellite magnetometer were compared during an interval of negative IMF $B_{z}$ conditions. The radar observed a L-shell aligned spectral width boundary around the dayside ionosphere. Simultaneously, Oersted observed high-frequency $(0.2-5 \mathrm{~Hz})$ magnetic field fluctuations. These magnetic field fluctuations are considered to be an Alfvén wave possibly associated with the particles which precipitate into the dayside high-latitude ionosphere when reconnection occurs. It has been theoretically predicted that the time-varying electric field is the dominant physical process to produce the broad radar Doppler spectral width (André et al., 2000b). Our observation clearly demonstrated that the boundary between narrow and broad spectral widths is corresponding well to the boundary in the level of the fluctuations, which supports the previous theoretical prediction. A close relationship between the electric and magnetic field fluctuations and particle precipitations during southward IMF conditions has been confirmed by many authors. The present observation allows us to suggest that the boundary between narrow and broad Doppler spectral widths observed in the dayside ionosphere is connected with the signature of the open/closed field line boundary, such as the cusp particle precipitations via electric and magnetic field fluctuations for the case of the negative IMF $B_{z}$ conditions.

Acknowledgements. The Ministry of Education, Culture, Sports, Science and Technology supports the SENSU Syowa HF radar systems. The 40th JARE (Japanese Antarctic Research Expedition) has carried out the HF radar operation at Syowa station. We are grateful for the support of the Oersted Project Office and the Oersted Science Data Centre at Danish Meteorological Institute. The Oersted Project is funded by the Danish Ministry of Transport, Ministry of Research and Information Technology, and Ministry of Trade and Industry. Additional support was provided by National Aeronautics and Space Administration (NASA), European Space Agency (ESA), Centre Nationale d'Etudes Spatiales (CNES), and Deutsche Agentur fur Raumfahrtangelegenheiten (DARA). The authors would like to thank N. Ness at Bartol Research Institute and CDAWeb for access to key parameter data from the MFI and SWE instruments onboard the ACE spacecraft. One of the authors (K.H.) is supported by a grant of Research Fellowships of the Japan Society for the Promotion of Science (JSPS) for Young Scientists.

Topical Editor T. Pulkkinen thanks A. Kozlovsky and J. Moen for their help in evaluating this paper.

\section{References}

André, R., Pinnock, M., and Rodger, A. S.: On the SuperDARN autocorrelation function observed in the ionospheric cusp, Geophys. Res. Lett., 26, 3353, 1999.

André, R., Pinnock, M., Villain, J.-P., and Hanuise, C.: On the factors conditioning the Doppler spectral width determined from SuperDARN HF radars, Int. J. Geomagn. Aeron., 2, 77, 2000a.

André, R., Pinnock, M., and Rodger, A. S.: Identification of the low-altitude cusp by Super Dual Auroral Radar Network radars:
A physical explanation for the empirically derived signature, J. Geophys. Res., 105, 27 081, 2000 b.

Baker, K. B., Greenwald, R. A., Villain, J.-P., and Wing, S.,: Spectral characteristics of high frequency (HF) backscatter from high latitude ionospheric irregularities: Preliminary analysis of statistical properties, Interim Rep., RADC-TR-87-284, Rome Air Dev. Cent., Griffis Air Force Base, N. Y., 1988.

Baker, K. B. and Wing, S.: A new magnetic coordinate system for conjugate studies of high latitudes, J. Geophys. Res., 94, 9139, 1989.

Baker, K. B., Dudeney, J. R., Greenwald, R. A., Pinnock, M., Newell, P. T., Rodger, A. S., Mattin, N., and Meng, C.-I.: HFradar signatures of the cusp and low latitude boundary layer, J. Geophys. Res., 100, 7671, 1995.

Baker, K. B., Rodger, A. S., and Lu, G.: HF radar observations of the dayside magnetic merging rate: A Geospace Environment Modeling boundary layer campaign study, J. Geophys. Res., 102, 9603, 1997.

Chisham, G., Pinnock, M., and Rodger, A. S.: The response of the HF radar spectral width boundary to a switch in the IMF $B_{y}$ directions: Ionospheric consequence of transient dayside reconnection?, J. Geophys. Res., 106, 191, 2001.

Erlandson, R. E. and Anderson, B. J.: Pc1 waves in the ionosphere: A statistical study, J. Geophys. Res., 101, 7843, 1996.

Feldstein, Y. I. and Starkov, G. V.: Dynamics of auroral belt and polar geomagnetic disturbance, Planet. Space Sci., 15, 209, 1967.

Greenwald, R. A., Baker, K. B., Dudeney, J. R., Pinnock, M., Jones, T. B., Thomas, E. C., Villain, J.-P., Cerisier, J.-C., Senior, C., Hanuise, C., Hunsucker, R. D., Sofko, G., Koehler, J., Nielsen, E., Pellinen, R., Walker, A. D. M., Sato, N., Yamagishi, H.: DARN/SuperDARN: A global view of high-latitude convection, Space Sci. Rev., 71, 763, 1995.

Hosokawa, K., Woodfield, E. E., Lester, M., Milan, S. E., Sato, N., Yukimatu, A. S., and Iyemori, T.: Statistical characteristics of Doppler spectral width as observed by the conjugate SuperDARN radars, Ann. Geophys., 20, 1213, 2002.

Hosokawa, K., Woodfield, E. E., Lester, M., Milan, S. E., Sato, N., Yukimatu, A. S., and Iyemori, T.: Interhemispheric comparison of spectral width boundary as observed by the SuperDARN radars, Ann. Geophys., 21, 1553, 2003.

Huber, M. and Sofko, G.: Small-scale vortices in the high-latitude F region, J. Geophys. Res., 105, 20 885, 2000.

Ishii, M., Sugiura, M., Iyemori, T., and Slavin, J. A.: Correlation between magnetic and electric field perturbations in the fieldaligned current regions deduced from DE 2 observations, J. Geophys. Res., 97, $13877,1992$.

Khan, H. and Cowley, S. W. H.: Observations of the response time of high-latitude ionospheric convection to variations in the interplanetary magnetic field using EISCAT and IMP-8 data, Ann. Geophys., 17, 1306, 1999.

Lyatsky, W. B., Malsev, Y. P., and Leontyev, S. V.: Threedimensional current system of magnetic substorm, Planet. Space Sci., 22, 1231, 1974.

Lysak, R. L. and Dum, C. T.: Dynamics of magnetosphereionosphere coupling including turbulent transport, J. Geophys. Res., 88, 365, 1983.

Matsuoka, A., Mukai, T., Hayakawa, H., Kohno, Y.-I., Tsuruda, K., Nishida, A., Okada, T., Kaya, N., and Fukunishi, H.: EXOS$\mathrm{D}$ observations of electric field fluctuations and charged particle precipitation in the polar cusp, Geophys. Res. Lett., 18, 305, 1991.

Matsuoka, A., Tsuruda, K., Hayakawa, H., Mukai, T., Nishida, A., 
Okada, T., Kaya, N., and Fukunishi, H.: Electric field fluctuations and charged particle precipitation in the cusp, J. Geophys. Res., 98, 11 225, 1993.

Maynard, N. C., Heppner, J. P., and Egeland, A.: Intense, variable electric fields at ionospheric altitudes in the high latitude regions as observed by DE-2, Geophys. Res. Lett., 9, 981, 1982.

Maynard, N. C.: Structure in the DC and AC electric fields associated with the dayside cusp region, in: The Polar Cusp, edited by Holtet, J. A. and Egeland, A., pp. 305-322, Reidel, D., Norwell, Mass., 1985.

Maynard, N. C., Aggson, T. L., Basinka, E. M., Burke, W. J., Craven, P., Peterson, W. K., Sugiura, M., and Weimer, D. R.: Magnetospheric boundary dynamics: DE-1 and DE-2 observations near the magnetopause and cusp, J. Geophys. Res., 96, 3505, 1991.

McWilliams, K. A., Yeoman, T. K., and Cowley, S. W. H.: Two dimensional electric field measurements in the ionospheric footprint of a flux transfer event, Ann. Geophys., 18, 1584, 2001a.

McWilliams, K. A., Milan, S. E., Yeoman, T. K., Sigwarth, J. B., Frank, L. A., and Brittnacher, M.: Interplanetary magnetic field $B_{y}$ dependence of the relative position of the dayside ultraviolet auroral oval and the HF radar cusp, J. Geophys. Res., 106, 29027,2001 b.

Milan, S. E., Lester, M., Cowley, S. W. H., Moen, J., Sandholt, P. E., and Owen, C. J.: Meridian-scanning photometer, coherent HF radar, and magnetometer observation of the cusp : a case study, Ann. Geophys., 17, 159, 1999.

Milan, S. E., Lester, M., and Yeoman, T. K.: HF radar polar patch formation revisited: summer and winter variations in dayside plasma structuring, Ann. Geophys., 20, 487, 2002.

Milan, S. E., Lester, M., Cowley, S. W. H., Oksavik, K., Brittnacher, M., Greenwald, R. A., Sofko, G., and Villain, J.-P.: Variations in polar cap area during two substorm cycles, Ann. Geophys., 21, 1121, 2003.

Moen, J., Carlson, H. C., Milan, S. E., Shumilov, N., Lybekk, B., Sandholt, P. E., and Lester, M.: On the correlation between dayside activity and coherent HF radar backscatter, Ann. Geophys., 18, 1531, 2001.

Newell, P. T. and Meng, C. I.: Mapping the dayside ionosphere to the magnetosphere according to particle precipitation characteristics, Geophys. Res. Lett, 19, 609, 1991.

Olsen, N., Holme, R., Hulot, G., Sabaka, T., Neubert, T., ToffnerClausen, L., Primdahl, F., Jorgensen, J., Leger, J.-M., Barraclough, D., Bloxham, J., Cain, J., Constable, C., Golovkov, V.,
Jackson, A., Kotze, P., Langlais, B., Macmillan, S., Mandea, M., Merayo, J., Newitt, L., Purucker, M., Risbo, T., Stampe, M., Thomson, A., and Voorhies, C.: Oersted Initial Field Model, Geophys. Res. Lett., 27, 3607, 2000.

Palmroth, M., Janhunen, P., Pulkkinen, T. I., and Peterson, W. K.: Cusp and magnetopause locations in global MHD simulation, J. Geophys. Res., 106, 29 435, 2001.

Pilipenko, V. A., Shalimov, S. L., Fedorov, E. N., Engebretson, M. J., and Hughes, W. J.: Coupling between field-aligned current impulses and Pi1 noise bursts, J. Geophys. Res., 104, 17419 , 1999.

Pinnock, M., Rodger, A. S., Baker, K. B., Lu, G., and Hairston, M.: Conjugate observations of the day-side reconnection electric field: A GEM boundary layer campaign, Ann. Geophys., 17, 443, 1999.

Rodger, A. S., Mende, S. B., Rosenberg, T. J., and Baker, K. B.: Simultaneous optical and HF radar observations of the ionospheric cusp, Geophys. Res. Lett., 22, 2045, 1995.

Schiffler, A., Sofko, G., Newell, P. T., and Greenwald, R. A.: Mapping the outer LLBL with SuperDARN double-peaked spectra, Geophys. Res. Lett., 24, 3149, 1997.

Smiddy, M., Burke, W. J., Kelley, M. C., Saflekos, N. A., Gussenhoven, M. S., Hardy, D. A., and Rich, F. J.: Effects of highaltitude conductivity on observed convection electric field and Birkeland currents, J. Geophys. Res., 85, 6811, 1980.

Sugiura, M., Maynard, N. C., Farthing, W. H., Heppner, J. P., Ledley, B. G., and Cahill Jr., L. J.: Initial results on the correlation between the magnetic and electric fields observed from the DE-2 satellite in the field-aligned current regions, Geophys. Res. Lett., 9, 985, 1982.

Trondsen, T. S., Lyatsky, W., Cogger, L. L., and Murphree, J. S.: Interplanetary magnetic field $B_{y}$ control of dayside auroras, J. Atmos. Terr. Phys., 61, 829, 1999.

Tsyganenko, N. A.: Modeling the Earth's magnetospheric magnetic field confined within a realistic magnetopause, J. Geophys. Res., 100, 5599, 1995.

Villain, J.-P., Greenwald, R. A., Baker, K. B., and Ruohoniemi, J. M.: HF radar observations of E-region plasma irregularities produced by oblique electron streaming, J. Geophys. Res., 92, $12327,1987$.

Yeoman, T. K., Lester, M., Cowley, S. W. H., Milan, S. E., Moen, J., and Sandholt, P. E.: Simultaneous observation of the cusp in optical, DMSP and HF radar data, Geophys. Res. Lett., 24, 2251, 1997. 